\title{
Steel telecommunication towers subjected to fire - case studies
}

\author{
J. Szafran \\ Chair of Reliability of Structures, Department of Structural Mechanics, Faculty of Civil Engineering, \\ Architecture and Environmental Engineering, Łódź University of Technology, Łódź, Poland \\ K. Juszczyk-Andraszyk \\ Compact-Project Company, Lódź, Poland
}

\begin{abstract}
The paper deals with three independent cases of lattice telecommunication towers subjected to elevated temperatures caused by fire. Each fire incident had a different background: a fire in a hall adjacent to the tower structure (case no. 1), a fire started deliberately (case no. 2), and a fire in a neighboring site (case no. 3). This comparison is relevant in that it involves towers of the same series of types (their structural components were made of the same type of steel sections), the only difference being height or the distance between their legs. The paper addresses the causes of each fire, degradation of the towers' structural members due to high temperature, estimated fire temperatures, and, most importantly, actions that should follow to continue safe operation of the structures. The results and descriptions of the activities carried out as well as conclusions drawn can be useful when analyzing similar cases of actual damage in such structures.
\end{abstract}

\section{INTRODUCTION}

One of the issues which can occur during steel telecommunication tower usage is fire in the neighborhood or fire of the tower itself. Structure is subjected to elevated temperatures which can cause damages or changes in the internal structure of steel. The aim of this paper is to analyze structural members of towers subjected to elevated temperatures and proposing operations to be taken to enable further safe usage of these structures.

\section{STEEL TOWER STRUCTURES ADDRESSED IN THE PAPER}

The structures that are discussed in this paper and were subjected to high fire temperatures are of the same series of types. All the towers are lattice structures with a cross-section being an equilateral triangle, legs made of round solid bars, and diagonal braces made of hot-rolled equal- and unequal-leg angles. Tower no. 1 is $26.5 \mathrm{~m}$ in height, while the other two towers (no. 2 and no. 3 ) are $50.5 \mathrm{~m}$ high. Figure 1 shows diagrams of the structures including their basic dimensions.

\section{CAUSES OF FIRE}

\subsection{Tower no. 1}

Tower structure no. 1 was exposed to elevated temperature due to a fire in a neighboring warehouse (Figure 2). Photographic documents, videos available online, and descriptions of 

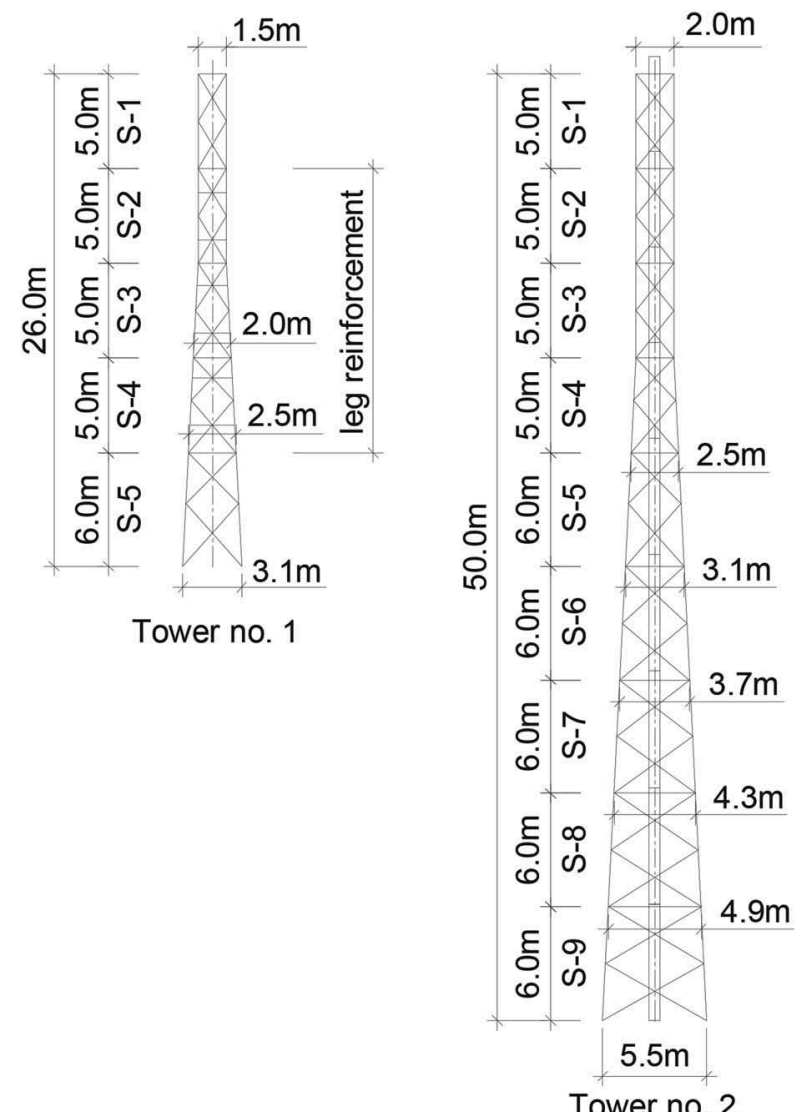

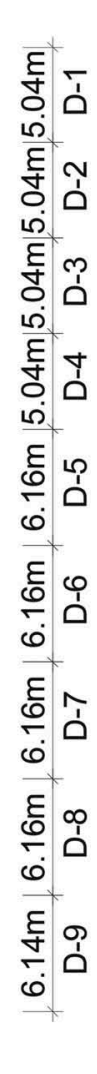

Tower no. 2

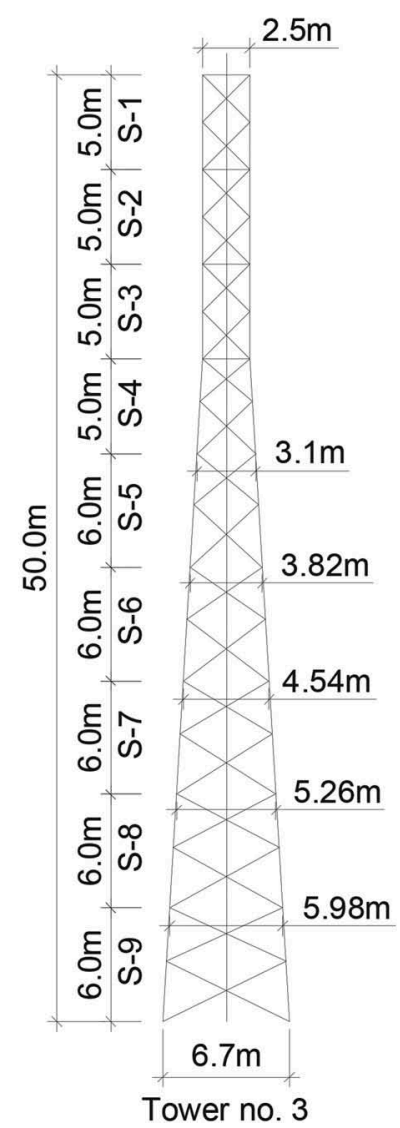

Figure 1. Diagrams of the telecommunication towers considered in the paper.
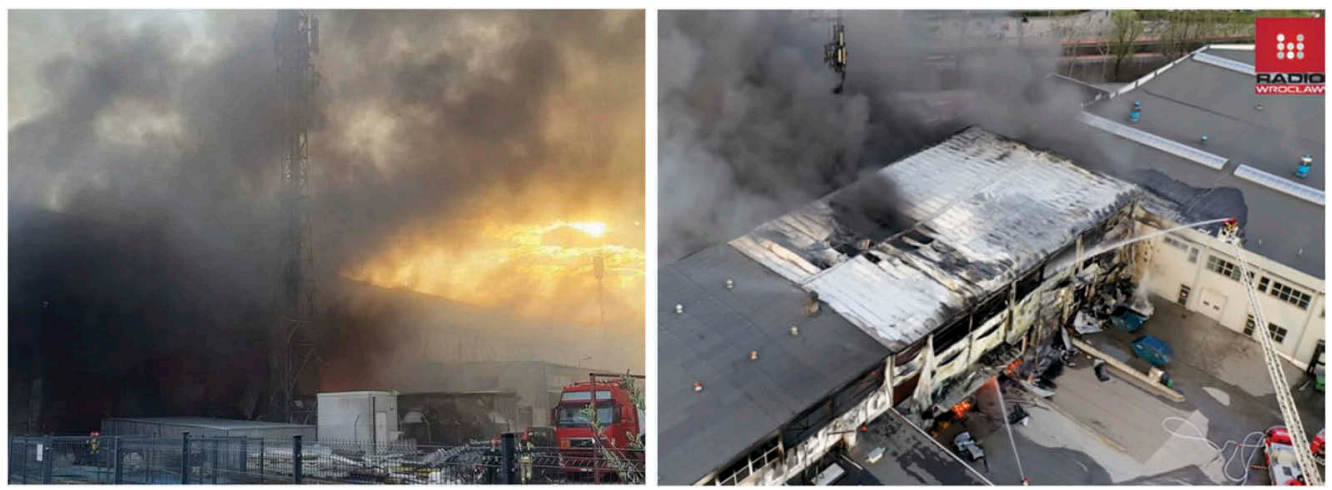

Figure 2. Fire in the warehouse adjacent to the tower (source: left - Gazeta Wrocławska; right - Radio Wrocław). 
a)

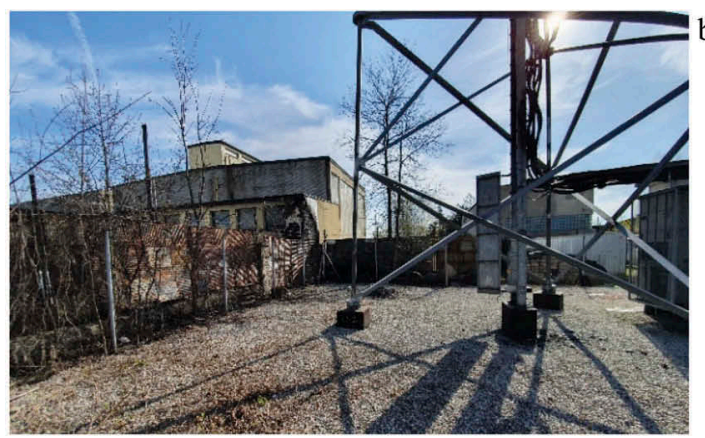

b)

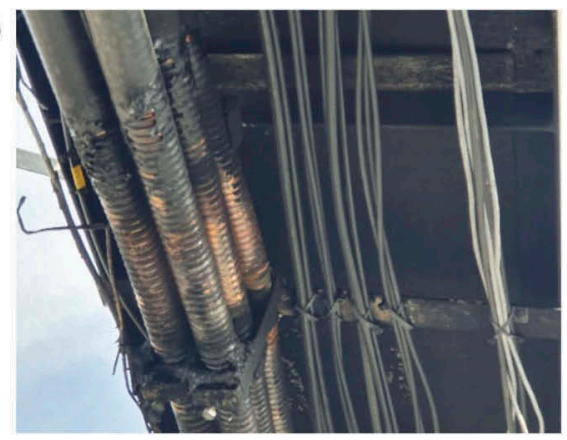

Figure 3. A) The area adjacent to the tower structure with visible distance between the area and the tower; b) Burnt polyethylene outer jacket of feeder cables.

the course of the incident indicate that the tower was subjected not directly to fire but to hot air (smoke) flowing in the tower's direction.

\subsection{Tower no. 2}

Tower structure no. 2 was exposed to high temperature when a neighboring warehouse and other facilities located in the adjacent industrial area were on fire (Figure 3) and also because cables started burning within a cable run between the tower structure and a telecom shelter.

Antenna cables seem to have been set on fire intentionally and independently of the fire in the nearby building. This opinion can be based on the following arguments: - the distance between the adjacent area where the fire occurred (Figure 3a) and the central part of the cable run is about $6.5 \mathrm{~m}$; - there is non-flammable breakstone on the ground of the base station area; - there are no other materials, including flammable ones, between the adjacent area and the tower structure, the cable run, and the cables; - the point where the antenna cables might have started burning is located directly under the crossing of bracing sections (Figure 3b); - damages and deformations of the cables were found from this point up to the right-hand side and then upwards.

\subsection{Tower no. 3}

Tower structure no. 3 was exposed to high temperature due to fire in a neighboring waste dump site (with household appliances and similar materials) and in a warehouse located in the same plot of land (Figure 4). As a consequence, a telecom shelter situated by the tower base was damaged (Figure 5). The fire might have been caused by spontaneous ignition of materials stored in the yard next to the base station area. Given the resulting damage and impact of the fire, this case was the most extreme one out of the three cases reported in the paper.

\section{ESTIMATED TEMPERATURES ACTING ON THE STRUCTURES}

When steel is exposed to elevated temperatures with access to fresh air, a colored layer forms on its surface. This layer contains iron oxides, and its color depends mainly on the temperature to which the steel component was exposed. The color of the layer is also affected by other factors, such as heating time, chemical composition of the steel, and thickness of the component, which is why assessment of temperature on the basis of the layer's color is approximate. At temperatures above $350{ }^{\circ} \mathrm{C}$ (the point when blue temper is formed), a characteristic, permanent blue color of steel is produced, but already at about $230-250{ }^{\circ} \mathrm{C}$ the layer turns yellowish. 


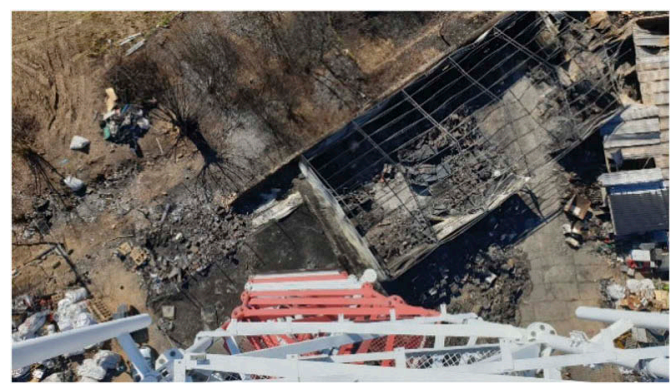

Figure 4. The adjacent area subjected to fire - the warehouse (top view).

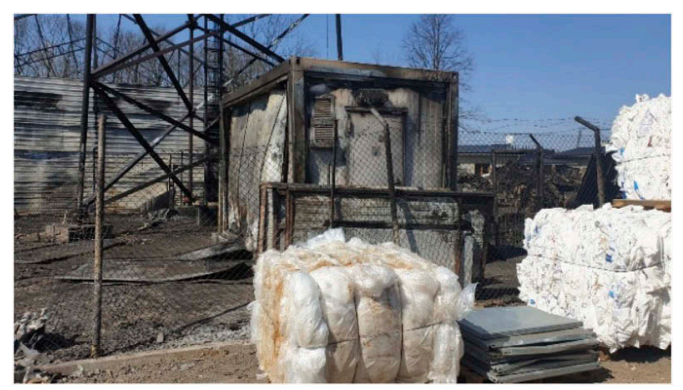

Figure 5. The telecom shelter destroyed during the incident.

The inference and arguments to estimate fire temperatures to which the structural members were exposed are provided below.

\subsection{Tower no. 1}

Since no plastic deformations of steel components of the structure and equipment were found, it can be concluded that the maximum temperature of the part of the tower that was exposed to the largest extent to this impact was $450{ }^{\circ} \mathrm{C}$. Considering that the layer was not found on the components of the structure, the temperature of air (smoke) can be assessed to have been lower. The outer jacket of the cable partly melted; the jacket was made of polyethylene whose melting point, depending on density of the material, is in the range between about 105 and $135^{\circ} \mathrm{C}$. Given the condition of cables (the outer jacket did not entirely melt; the corrugated copper layer underneath was not exposed), the temperature within S-3 segment was very likely within this range, while in other parts of the tower it was lower.

\subsection{Tower no. 2}

A yellow layer can be seen in Figure 6, which shows that the components were heated to less than $250^{\circ} \mathrm{C}$. This makes it possible to state that the fire temperature was relatively low (in the context of fire conditions). Ladder components deformed as a result of the combination of factors: elevated temperature, small thickness of the components' walls $(4 \mathrm{~mm})$, and strong constrainment both in the longitudinal axis (the lower part is fixed to the ladder foundation, while the upper one is rigidly connected to the next segment of the ladder) and perpendicularly through rungs and pieces designed to fasten cables). 

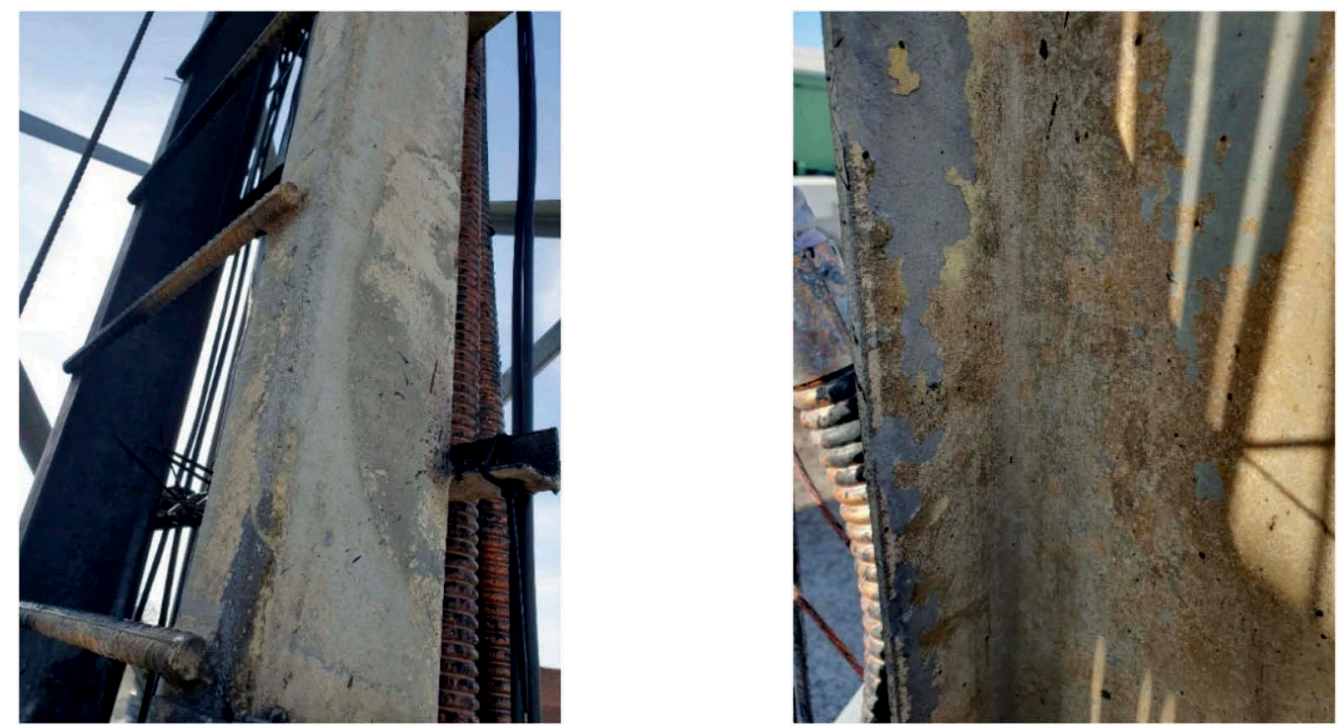

Figure 6. The effect of elevated temperature on components of the ladder rails (D-8 element).

The outer jacket of the cable melted; the jacket was made of polyethylene whose melting point, depending on density of the material, is in the range between about 105 and $135{ }^{\circ} \mathrm{C}$. Given the condition of cables (most of the outer jacket melted; the corrugated copper layer underneath was exposed - Figure 3b), the temperature within D-9 segment of the ladder was very likely between $105^{\circ} \mathrm{C}$ and $250{ }^{\circ} \mathrm{C}$; this description only relates to components used in lower segments of the access and cable ladder.

\subsection{Tower no. 3}

Since no plastic deformations of steel components of the structure and equipment were found, it can be concluded that the maximum temperature of the part of the tower that was exposed to the largest extent to this impact was $450{ }^{\circ} \mathrm{C}$. The blue temper was found on bracing sections of the bottom segment of the tower (Figure 7). Some deformation of the zinc coating on these sections can also be seen (zinc melting point is about $450{ }^{\circ} \mathrm{C}$ ). Diagonal braces depicted in Figure 7 were the closest to where waste was stored and then burnt in the waste dump site. Thus, a conclusion may be drawn that the components that were exposed to the fire temperature to the largest extent lost their formability and at the same time the brittleness of the material increased (particularly if during firefighting operations water was directly poured on the components and they quickly cooled down).

\section{STRENGTH PROPERTIES AND USABILITY OF STRUCTURES AFTER EXPOSURE TO FIRE}

Elevated temperatures decrease strength properties of steel and change its physical and mechanical properties. The relation shown in Figure 8 is recommended by Eurocode 3 to determine reduced values of quantities such as Young's modulus and the yield point.

According to (Tide, 1998), if hot-rolled steel is soaked for 3 hours at temperatures as high as $600{ }^{\circ} \mathrm{C}$ and then cooled down to the room temperature, its original mechanical properties are generally the same. The results of tests on samples taken from steel components that had been exposed to fire, provided in (Zhong, 2015), also show only a minor permanent reduction in the yield point. It should be noted, however, that the properties of structural steel after exposure to 

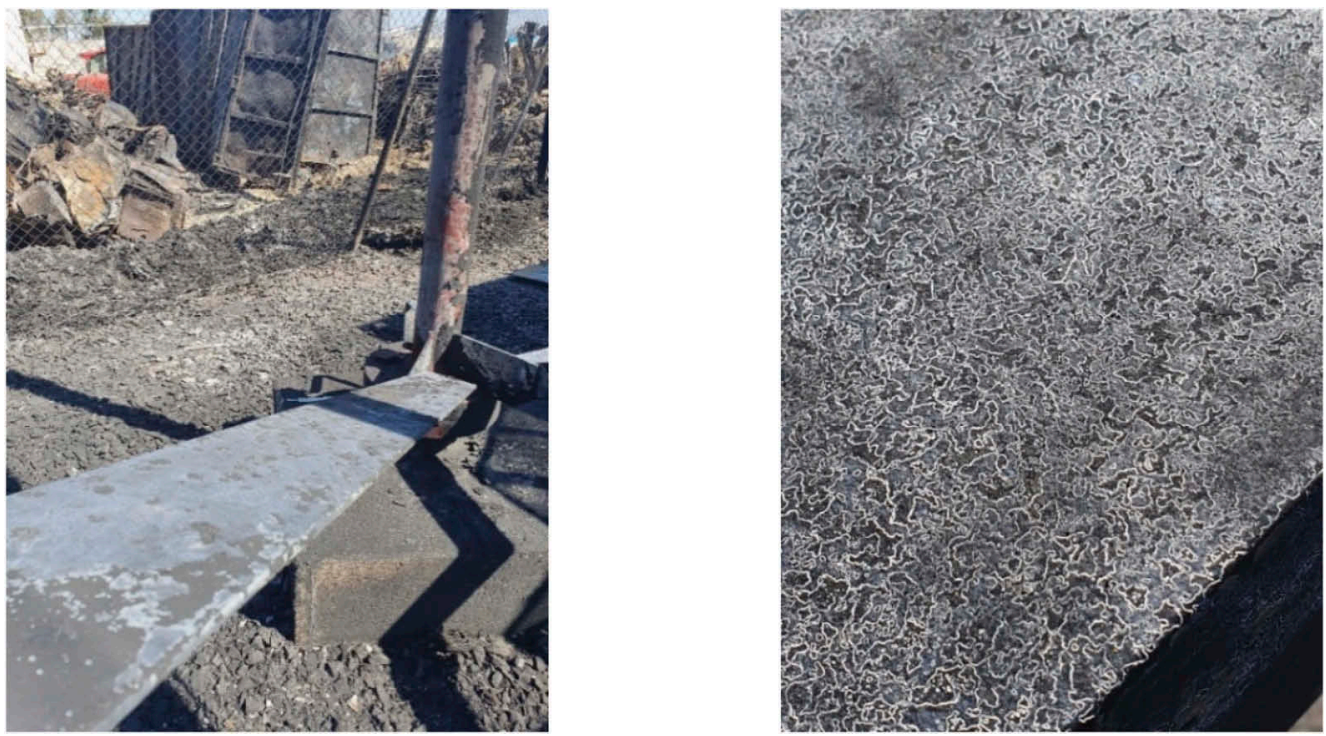

Figure 7. The blue temper on bracing sections in the bottom segment of the tower.

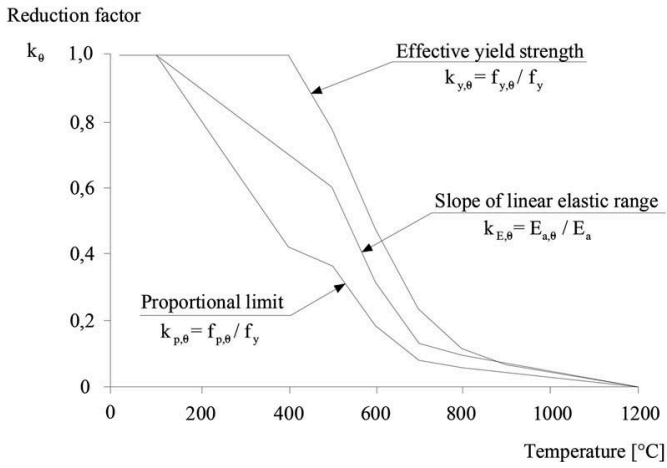

Figure 8. Reduction factors in the stress - strain relationship for carbon steel at elevated temperatures.

fire are also affected by structural changes which can occur in this material even when the threshold temperature related to recrystallization was not reached. Such changes generally lead to a significant increase in the material's susceptibility to brittle cracking (Maślak, 2012). Another type of impact caused by fire that should be taken into account is the potential of rheological effects, mainly the impact of steel creeping which intensifies at high temperatures, and stress decay that often accompanies the creeping behavior. What is also essential is how many times the components heated and partly cooled down during the fire incident, and how fast these processes occurred. When assessing the usability of components of a structure, one should consider the distribution of internal stresses that was generated thermally in these components and has an adverse effect in terms of future static operation, even if the components show no sign of major deformation or straining. What need to be emphasized is that various types of structural changes that are disadvantageous mainly due to reducing formability of materials freely occur in the material at temperatures much lower than $350{ }^{\circ} \mathrm{C}$. These changes are permanent and must not be ignored when the material, once cooled down, is assessed (Outinen \& Mäkeläinen, 2002). 


\section{CONCLUSIONS}

Based on the above information on the estimation of the temperature to which the structure is exposed during a fire, as well as visual inspection and analysis of structural elements, several conclusions can be drawn. The temperature to which the elements of tower no. 1 were exposed was in the range of $135-230^{\circ} \mathrm{C}$. In future analyses of the load-carrying capacity of the tower structure under variable load conditions (different number of antennas and cables mounted), Young modulus of steel within lower segments should be reduced by $10 \%$ (Maślak, 2020). In the case of tower no. 2 one can conclude that the temperature acting on ladder segments did not exceed $250^{\circ} \mathrm{C}$. The fire was local and the bearing elements were not exposed to elevated temperature. Young modulus of ladder members in lower sections should be reduced (by $15 \%-$ safe value), but taking into account their deformations during fire, the bottom segment of the ladder should be replaced. Tower no. 3 was subjected probably to the highest temperature - in the range of $350-450^{\circ} \mathrm{C}$. In this case not only Young modulus of steel should be reduced in future analyses of load-carrying capacity (by about 35\%), but also yield strength (reduction by $10 \%$ ). The safe solution that was used in this case is replacing bracing sections of the bottom segment (due to increased brittleness of steel) and adding crosswise supports of the legs.

\section{REFERENCES}

Maślak, M. 2012. Badania stali konstrukcyjnej po pożarze w kontekście oceny możliwości jej dalszego użytkowania w ustrojach nośnych elementów budowlanych. Przegląd Budowlany 6/2012, 48-51 (in Polish).

Maślak, M. 2020. Zachowanie się stali konstrukcyjnej w warunkach pożaru. Materialy, nowoczesne technologie, realizacje konstrukcji stalowych,173-230 (in Polish).

Outinen, J. \& Mäkeläinen, P. 2002. Mechanical properties of structural steel at elevated temperatures and after cooling down. Proceedings of the Second International Workshop "Structures in Fire", March 18 - 19, 2002, Christchurch, New Zealand, 273-289.

Tide, R.H.R. 1998. Integrity of Structural Steel After Exposure to Fire. Engineering Journal, first quarter.

Zhong, T. 2015. Mechanical properties of prestressing steel after fire exposure. Materials and Structures 48, 3037-3047. 